\title{
Caracterización del sistema presupuestario autonómico: el caso de Murcia
}

\author{
José Francisco Bellod Redondo \\ Departamento de Economía \\ Universidad Politécnica de Cartagena
}

Sumario: 1. INTRODUCCIÓN. 2. FASES DE ELABORACIÓN DEL PRESUPUESTO. MANIFESTACIÓN DEL SISTEMA PRESUPUESTARIO. 3. DEBATE Y APROBACIÓN DEL PRESUPUESTO. 4. LIQUIDACIÓN DEL PRESUPUESTO. DISCRECIONALIDAD. 5. CONCLUSIONES.

\section{INTRODUCCIÓN}

En este trabajo pretendemos analizar la evolución del sistema presupuestario en el ámbito autonómico, concretamente en el caso de la Comunidad Autónoma de la Región de Murcia, en el periodo 1983-2006. Concretamente queremos saber si en estos 20 años de experiencia autonómica se han dado las condiciones necesarias para la superación del sistema de «Presupuestos Administrativos» heredados de la Hacienda Estatal y con los que la Comunidad Autónoma inició su andadura.

Para ello es conveniente, en primer lugar, fijar el concepto de «sistema presupuestario».

En palabras de Sánchez Revenga (1989, p. 42), el presupuesto «...como técnica, tiene una metodología, unas normas y reglas que es preciso dominar para la utilización de todas las posibilidades que nos ofrece este instrumento de previsión» ${ }^{1}$. De lo contrario el proceso presupuestario sería estéril, dando lugar a un documento sin operatividad y sin posibilidad de traslación práctica al mundo real.

En la historia de la Hacienda Pública han visto la luz diversos sistemas presupuestarios o técnicas de presupuestación. El Presupuesto Administrativo $o$ de Medios, considerado el punto de partida de todas las técnicas presupuestarias modernas; el Presupuesto de Ejecución, que se introdujo en la Administración estadounidense a principios de los años 50, tomando como punto de partida los trabajos de economistas especializados en el análisis de la adopción de decisiones en el seno de las organizaciones; el Presupuesto Planificado por Programas, sin lugar a dudas el sistema presupuestario que, al menos en apariencia, ha logrado más arraigo en las administraciones públicas del

\footnotetext{
${ }^{1}$ Véase J. SÁnchez Revenga (1989), Presupuestos Generales del Estado y Aspectos Básicos del Presupuesto General de las CEE. Ariel Economía, Barcelona.
} 
mundo desarrollado, y cuya principal aportación fue la incorporación del análisis coste-beneficio ${ }^{2}$ como técnica de apoyo en la selección de programas presupuestarios $^{3}$. Finalmente, el Presupuesto Base Cero (ZBB, Zero Base Budgeting), introducido en la Administración estadounidense en los años setenta, trata de flexibilizar y racionalizar al máximo el proceso de programación presupuestaria exigiendo «la justificación de la totalidad de las asignaciones presupuestarias, no garantizando que los programas existentes vayan a permanecer en el futuro, pudiendo ser sustituidos por programas nuevos» ${ }^{4}$.

Con el Presupuesto Administrativo se pretendía, ante todo, controlar el destino de los fondos públicos y, en la medida de lo posible, la disposición de los mismos por parte del soberano. A partir de los años 50, la pretensión de los presupuestadores consiste en cómo gastar mejor y, a raíz de la quiebra del ideario keynesiano y de la exorbitante ascensión del déficit público en los años 70, la preocupación es cómo contener el gasto. En palabras de Tsarchys (1981), «los esfuerzos para cerrar el vacio deficitario han incluido un número tremendo de medidas, tanto por el lado de los ingresos del Presupuesto como por el lado del gasto...después de décadas de continuados aumentos del gasto, el enfoque se ha desplazado a un examen de las opciones decrecientes, así como a recortes efectivos en los organismos y los programas. Al mismo tiempo existe un menor optimismo acerca de los efectos prácticos de las técnicas de racionalidad presupuestaria (PPBS, RCB, Presupuesto base cero) de aquel que se observaba en los años sesenta y primeros setenta» ${ }^{5}$.

En este sentido resulta obligado remarcar que los sistemas presupuestarios importados a nuestro cuerpo normativo habían pasado al menos por tres filtros empíricos: el de las empresas privadas en las cuales tuvieron su origen; el de las diversas administraciones norteamericanas (que las importaron al ámbito público) y, finalmente, el de la Administración española, así como de otras Administraciones de nuestro entorno. Pero como indica Zapico Goñi (1996), «...después de más de veinte años (1960-1980) intentando realizar

\footnotetext{
${ }^{2}$ Sobre las características metodológicas de la técnica PPBS pueden consultarse las siguientes obras: E. Albi IbáÑeZ, Introducción al Análisis Coste Beneficio, 1992, IEF, Madrid; E. Albi IbáÑez, J. M. GonzÁlez-PÁramo y G. López Casasnovas, Gestión Pública, Editorial Ariel, Barcelona, 2000; E. Albi IbÁÑez, J. M. GonzÁlez-PÁramo e I. Zubiri, Economía Pública I y II, Editorial Ariel, 2000, Barcelona; R. Layard, Análisis Costo Beneficio, Fondo de Cultura Económica, México, 1978.

${ }^{3}$ Como indican A. García Villarejo y J. Salinas Sánchez, en Manual de Hacienda Pública (1992, p. 192), Tecnos, Madrid: «...mientras que el presupuesto de ejecución se ocupa del proceso presupuestario intentando seleccionar los mejores métodos para la gestión de un programa dado, el PPBS se ocupa de los objetivos del presupuesto intentando seleccionar para su ejecución los programas más adecuados».

${ }^{4}$ Véase de I. Montalvo Correa (1995), «El Presupuesto Base Cero como Instrumento para la Asignación Eficiente de Recursos», Cuadernos de Actualidad, no 4, Instituto de Estudios Fiscales, Ministerio de Economía y Hacienda, Madrid.

${ }^{5}$ Véase D. Tsarchys, «El Control del Déficit Público» (1981), en Lecturas de Hacienda Pública, Ed. Juan Francisco Corona, Minerva Ediciones.
} 
grandes reformas presupuestarias, la mayoría de los países europeos quedaron convencidos de la necesidad de aproximarse a éstas con una perspectiva más pragmática y menos comprensiva...el fracaso en el intento de implantar sistemas o modelos racionales de presupuesto (PPBS, RCB, ZBB etcétera) ha sido generalizado» ${ }^{6}$.

A ello hay que sumar un hecho muy significativo pero de cuya relevancia pocas veces se tiene verdadera conciencia: al ser la Comunidad Autónoma una administración nueva, no sólo su cuerpo jurídico estaba en fase de creación y expansión, sino que otro tanto sucedía con su organigrama jerárquico y con el personal a su servicio. Teniendo en cuenta las advertencias de los especialistas acerca de la importancia de los sujetos que intervienen en el proceso presupuestario (entre ellos los funcionarios), ello hubiera debido facilitar, al menos en teoría, la introducción de técnicas presupuestarias novedosas, sin tener que afrontar el problema de reciclar a funcionarios formados e instalados en mentalidades y procedimientos desfasados. Sin embargo, esto no parece haber sido así, a tenor de los resultados obtenidos.

\section{FASES DE LA ELABORACIÓN DEL PRESUPUESTO. MANIFESTACIÓN DEL SISTEMA PRESUPUESTARIO}

La «elaboración» es la fase del proceso presupuestario que se inicia con la confección del anteproyecto de Ley de Presupuestos y culmina con su aprobación por el órgano legislativo. Dos principios rectores del proceso presupuestario son de especial importancia en esta fase: el principio de competencia y el principio de temporalidad.

\section{Cuadro 1}

Elaboración del presupuesto

\begin{tabular}{|l|l|}
\hline \multicolumn{1}{|c|}{ FASE EJECUTIVA } & FASE LEGISLATIVA \\
\hline - Recopilación de anteproyectos de gasto. & - Debate de Totalidad. \\
- Elaboración del anteproyecto de ingresos. & - Enmiendas parciales. \\
- Aprobación del Proyecto de Ley. & \\
\hline
\end{tabular}

La primera fase, a la que nos referiremos con el término «fase ejecutiva», se inicia con la aprobación de la Orden del Consejero de Hacienda solicitando - a los centros gestores de gasto con dotaciones presupuestarias diferenciadas- la remisión de sus anteproyectos de presupuesto, y tiene como resultado el Proyecto del Ley de Presupuestos. Esta fase incluye el proceso de obtención de los Anteproyectos de Gasto de las distintas Consejerías, su integración en un Anteproyecto único por la Consejería de Hacienda y su re-

\footnotetext{
${ }^{6}$ Véase E. ZAPICO GoÑ (1996, p. 93), «Presupuesto por Programas Versus Incrementalismo Presupuestario ¿Un Falso Dilema?», Papeles de Economía Española, $\mathrm{n}^{\circ} 69$.
} 
misión al Consejo de Gobierno, de donde finalmente se obtiene el Proyecto de Ley del Presupuestos Generales de la Comunidad Autónoma de la Región de Murcia.

La segunda fase, que denominaremos «fase legislativa», se inicia con la entrada de dicho texto en la Asamblea Regional de Murcia y finaliza con la aprobación de la Ley de Presupuestos.

En la «fase ejecutiva» de elaboración presupuestaria es posible identificar con claridad el sistema presupuestario que caracteriza a cualquier Administración. Los presupuestos de 1985 introdujeron como gran novedad — prácticamente recién nacida la Comunidad Autónoma - la «Presupuestación por Programas» (PPBS). El preámbulo de la Ley de Presupuestos para 1985 es una declaración de intenciones tan nítida como fallida: «Se inicia un importante proceso de reforma y modernización de la Administración Pública, cumpliendo así, un compromiso anunciado por el Consejo [de Gobierno]; se presentan unos presupuestos por programas u objetivos, con la finalidad de conseguir una utilización racional y eficaz de los recursos públicos y dar transparencia, a través de una información detallada y suficiente, a la politica presupuestaria del Consejo de Gobierno. La presupuestación por programas de gasto permitirá no solo mejorar el nivel de eficacia en la asignación de los recursos públicos de esta Comunidad Autónoma, sino que también posibilitará la evaluación, a posteriori, del grado de cumplimiento de los programas presupuestados, generando un sistema de información más adecuado en la administración de los fondos públicos, dado su carácter vinculante para los órganos de gestión y decisión de la Comunidad Autónoma».

Más concretamente, en la «Presentación» de dicho Proyecto de Ley, el Gobierno Regional, en relación con el sistema de presupuestación PPBS se manifiesta en el siguiente sentido: «En términos generales, se trata de adaptar las técnicas de la empresa privada a la actuación de las administraciones públicas. Detectar el fallo de gestión, especificando los objetivos y las actividades, permitiendo a su vez saber qué actividades no se han cumplido. Permite corregir también, actuaciones presupuestarias, así como depurar responsabilidades. En resumen, determina: cuánto debemos gastar, por qué debemos hacerlo y si lo hacemos en forma óptima» ${ }^{7}$.

En los ejercicios siguientes la presupuestación por programas siguió contemplándose como un baluarte fundamental del sistema presupuestario regional. El Preámbulo de la Ley de Presupuestos para 1987, por ejemplo, se expresaba en el siguiente sentido: «La Ley de Presupuestos Generales de la Comunidad Autónoma para 1987 se ha elaborado, una vez más, mediante la técnica de presupuestación por programas de gasto. Con ello se profundiza en la explicación de procedimientos que permiten una racional utilización

\footnotetext{
${ }^{7}$ Proyecto de Ley de Presupuestos de la Comunidad Autónoma de la Región de Murcia para 1985, tomo 1, página 16.
} 
de los recursos públicos disponibles y una exposición adecuada de sus objetivos y finalidades».

Al menos en apariencia, el Gobierno regional era consciente de las complejas implicaciones metodológicas de cambiar el sistema de Presupuestos Administrativos por el sistema PPBS. Así se desprende del citado documento, en el que se esboza la metodología de elección entre programas presupuestarios alternativos: «...se trata de resolver la tensión, clásica en la economía, de deseos ilimitados y recursos escasos. Procediendo a la elección entre todos los programas, con el fin de decidir cuáles deben realizarse con cargo a las dotaciones del año y cuáles deben quedarse postergados para ejercicios siguientes. Para la realización de esta fase del proceso presupuestario se requiere la valoración de costes del programa y los beneficios que se esperan alcanzar con él. En la cuantificación de los costes deberá tenerse en cuenta todos los gastos que el programa conlleva, personal, bienes y servicios, transferencias, inversiones, etc. Se establecerá idéntico proceso para los beneficios. Debe señalarse que esta segunda valoración implica una especial dificultad por la existencia de efectos externos en la mayoría de los bienes y servicios que generan los programas de actuación pública. Su medición se hace en muchos casos muy dificultosa y en algunos, hasta inviable» ${ }^{8}$.

En realidad, tanto entonces como en el resto de historia autonómica, los presupuestos nunca se confeccionaron de acuerdo a la metodología PPBS, de modo que lo que se denominó Presupuestación por Programas fue, simple y llanamente, una presentación sofisticada del tradicional Presupuesto Administrativo. Si nos atenemos a las Órdenes de elaboración de los presupuestos aprobadas cada año por la Consejería de Hacienda, descubrimos que en ellas no se contiene metodología alguna asimilable al sistema PPBS. En otras palabras: el presupuesto se clasificaba en programas pero los programas no se elegían ni se dotaban en función de análisis coste-beneficio o similar, ni tampoco eran utilizados a posteriori para evaluar la eficacia ni la eficiencia del gasto público.

En 1997 se introduce lo que pretendía ser un sistema de seguimiento por objetivos de los programas presupuestarios ${ }^{9}$ que hubiera permitido aproximar el sistema presupuestario regional a los requisitos de un sistema PPBS. Sin embargo, ni por el alcance de la reforma (sólo afecta a 4 de los más de 100 programas presupuestarios existentes) ni por su metodología se trata de un cambio cualitativo en el sistema presupuestario regional. Este resultado coincide con las aseveraciones de Albi, González-Páramo y López Casasnovas (2000, p. 198) según los cuales «la literatura sobre presupuestación por programas en España coincide en señalar que la estructura presupuestaria española sigue siendo fundamentalmente orgánica o administrativa. Los pro-

\footnotetext{
8 Ídem, páginas 17 y 18.

${ }^{9}$ Mediante la Disposición Adicional Octava de la Ley de Presupuestos para 1997.
} 
gramas tienden a ser el resultado de la agregación de gastos por servicios de acuerdo con objetivos nominales poco útiles en el ámbito de la asignación de recursos. La definición de objetivos tiene como peso fundamental la definición de las competencias legales de los servicios o unidades que intervienen. Los indicadores propuestos se plantean básicamente en términos de los recursos usados, y no se cuenta con estrategias amplias. Los sistemas de información no siempre generan los datos adecuados» ${ }^{10}$.

La presunta «Presupuestación por Programas» caracterizó el sistema presupuestario regional durante el periodo (1985-1995), es decir, durante los Gobiernos del PSOE. Con el triunfo electoral del PP en 1995 el proceso presupuestario se ve afectado, entre otras cosas, por el anuncio de la reforma en el sistema presupuestario y la introducción de la metodología Presupuesto Base Cero (ZBB). Como el presupuesto de 1996 era un presupuesto de transición por haberse producido la alternancia en el Gobierno a mediados de 1995, la plena entrada en vigor del nuevo sistema presupuestario habría de dejarse sentir en el presupuesto de 1997: «La elaboración de los Presupuestos Generales de 1996 se caracteriza por el comienzo del cambio organizativo que pretende realizar el nuevo Consejo de Gobierno y que se materializará totalmente durante el mencionado ejercicio 96, así como mediante la utilización de la técnica de presupuestación base-cero para 1997» ${ }^{11}$.

La preparación del presupuesto para 1997 habría de constituir el bautismo de fuego del sistema ZBB y con ese objetivo se reformaron algunos aspectos del proceso burocrático de la elaboración presupuestaria (aparte del ya citado sistema de seguimiento por objetivos): «Las principales novedades que se introducen... al objeto de que la elaboración de los presupuestos para 1997 esté presidida por los criterios de eficacia y eficiencia...son las siguientes: 1)Se concede una importancia fundamental a la presupuestación por objetivos, como instrumento para la asignación racional de los recursos...2) Introducción de mejoras técnicas en materia presupuestaria dando los primeros pasos en la implantación de la técnica del Presupuesto en Base Cero con el objetivo de racionalizar el gasto y adaptando el contenido de las fichas $^{12}$ a las necesidades de información que requiere la evaluación de las dotaciones presupuestarias a asignar a los objetivos de los Programas» ${ }^{13}$.

Nuevamente la reforma se limitó básicamente a una mayor sofisticación del Presupuesto Administrativo: se perfeccionó la información presupuesta-

\footnotetext{
${ }^{10}$ Véase E. Albi, J. M. González-Páramo y G. López Casasnovas, Gestión Pública, Ariel, Barcelona.

${ }^{11}$ Orden de 20 de julio de 1995, de la Consejería de Economía y Hacienda, por la que se dictan normas para la elaboración de los Presupuestos Generales de la Región de Murcia para 1996.

${ }^{12}$ Se refiere a los estadillos contables a cumplimentar por los Directores de cada centro de gasto con la información presupuestaria relativa a cada programa presupuestario gestionado.

${ }^{13}$ Orden de 14 de mayo de 1996, por la que se dictan normas para la elaboración de los Presupuestos Generales de la Región de Murcia para 1997.
} 
ria mediante la inclusión de la estimación de los beneficios fiscales (Presupuestos de 1996), la distinción entre subvenciones y transferencias (1996), la inclusión de un anexo con la relación de compromisos con cargo a ejercicios futuros (1996), la consolidación funcional en el Proyecto de Ley de Presupuestos presupuesto (Presupuesto de 1997), la introducción de un sistema de seguimiento de los programas presupuestarios (1997) y la remisión mensual de las liquidaciones presupuestarias a la Asamblea Regional de Murcia así como de las modificaciones presupuestarias ${ }^{14}$ (1998).

Sin embargo, al igual que sucediera con la reforma PPBS (1985), tanto la creación / supresión de programas, como su dotación presupuestaria se decidía en función de criterios financieros y de oportunidad política (obviamente legítimos en democracia) pero sin una metodología específica propia del análisis coste-beneficio. En última instancia, es el Consejo de Gobierno quien decide sobre la configuración definitiva de los programas presupuestarios a integrar en el Proyecto de Ley de Presupuestos si bien, a partir de la década de los 90 las normas para la elaboración de los presupuestos preveían la posibilidad de que dichos programas fuesen examinados previamente por órganos creados ad hoc. Los dos órganos más importantes creados a tal efecto fueron la Comisión o Comisiones de Análisis de Programas y el Comité de Planificación Económica Regional ${ }^{15}$. El primero no tiene carácter estable y su constitución es potestad del Director General de Presupuestos, teniendo por objeto, en la práctica, ajustar las dotaciones de los programas remitidos por cada centro gestor a las directrices establecidas por el Consejero de Economía y Hacienda en la correspondiente norma de elaboración de presupuestos ${ }^{16}$. El cometido del Comité de Desarrollo Económico Regional es mucho más específico: fijar el orden de prioridad en los proyectos de inversión propuestos por los distintos centros gestores de gasto y adecuarlos a la planificación económica regional ${ }^{17}$. Sin embargo, nada concretan las normas de elaboración de presupuestos sobre la metodología a emplear, salvo un llamamiento genérico a favor de la rentabilidad económica y social del presupuesto ${ }^{18}$.

Los teóricos de las instituciones presupuestarias han identificado la influencia de las normas de procedimiento sobre el déficit público ${ }^{19}$. En primer lu-

\footnotetext{
${ }^{14}$ Convenio de 2 de abril de 1998, entre la Asamblea Regional de Murcia y la Consejería de Economía y Hacienda.

${ }^{15}$ Rebautizado Comité de Desarrollo Económico Regional a partir de 1996.

${ }^{16}$ Orden de 14 de mayo de 1996: «...bajo la presidencia del Director General de Presupuestos y Finanzas, podrán constituirse comisiones de análisis de programas, en los que participarán los Directores Generales de los Centros Gestores y los técnicos que se considere conveniente».

${ }^{17}$ Particularmente al Plan de Desarrollo Regional y al Plan de Reactivación Económica.

${ }^{18}$ Por ejemplo, la citada Orden de 14 de mayo de 1996, establece: «1. La elaboración del presupuesto se basará en ...c) La decisión sobre los proyectos de inversión a incluir en dicho presupuesto en función de su rentabilidad económica y social en función de los objetivos definidos».
}

${ }^{19}$ Véase A. Alesina y R. Perotti, R. (1995), «The Political Economy of Budget Deficits», IMF Staff 
gar, el resultado del proceso presupuestario dependerá del carácter jerárquico o colegial de los órganos competentes en materia presupuestaria. A mayor jerarquización se prevé mayor rigor presupuestario. Si nos referimos a la primera fase de la elaboración presupuestaria, los órganos competentes, bien unipersonales (Consejeros) bien pluripersonales (Consejo de Gobierno), conforman una organización fuertemente jerarquizada. El Presidente del Consejo de Gobierno (y Presidente de la Comunidad Autónoma) ocupa una posición singular en la jerarquía del poder ejecutivo: entre sus atribuciones se hallan, por ejemplo, algunas tan relevantes como nombrar y cesar a los restantes miembros del Consejo de Gobierno, proponer el programa legislativo del Gobierno regional y coordinar la elaboración de los proyectos de Ley o resolver los conflictos de atribuciones entre dos o más Consejerías ${ }^{20}$. Además, tal y como indicábamos anteriormente, en la historia de la Comunidad Autónoma de la Región de Murcia siempre ha coincidido la Presidencia de la Comunidad Autónoma con el liderazgo del partido político mayoritario y con el de su grupo parlamentario. En tales condiciones, resulta absurdo pensar que los miembros del Consejo de Gobierno puedan sostener con firmeza posiciones de confrontación con el Presidente de la Comunidad Autónoma.

Cosa distinta es que el Consejero de Hacienda haya ocupado un papel preeminente en la organización política de la Comunidad Autónoma. Aunque legalmente esa preeminencia está reconocida desde el momento en que se le atribuye, con carácter exclusivo, determinadas competencias en materia presupuestaria, el papel de los Consejeros de Hacienda de la Región de Murcia dista de ser la que corresponde a un Ministro de Hacienda en el ámbito anglosajón (del cual proviene buena parte de la literatura especializada en las instituciones presupuestarias). Como órgano unipersonal integrador del Anteproyecto de Ley de Presupuestos, le corresponde al Consejero de Hacienda, en apariencia, un poder de veto en materia presupuestaria, pudiendo presentar al Consejo de Gobierno de la Comunidad Autónoma un anteproyecto cualitativa y cuantitativamente distinto de la mera suma aritmética de los anteproyectos remitidos por cada Consejería, esto es, puede, teóricamente, modificar la voluntad política que los restantes miembros del Consejo de Gobierno han manifestado por medio de los Anteproyectos remitidos. Así, la LHRM establece en su artículo 30: «La Consejería de Economía y Hacienda, examinados los referidos anteproyectos de gastos y la estimación de in-

\footnotetext{
Papers, vol. 42, marzo [versión española en Papeles de Economía Española $\mathrm{n}^{\circ}$ 68, 1996]. También de A. Alesina y R. Perotti (1996), «Budget Deficit and Budget Institutions», NBER Working Paper, $\mathrm{n}^{\circ} 5556$ [versión española en Papeles de Economía Española n $^{\circ}$ 68, 1996]. J. Von Hagen (1992), «Budgeting Procedures and Fiscal Performance in the European Communities», EEC Commission, Economic Papers, $\mathrm{n}^{\circ}$ 96, y J. Von Hagen e I. Harden (1994), «National Budget Processes and Fiscal Performance», European Economy Reports and Studies, ${ }^{\circ} 3$ [versión en español en Papeles de Economía Española, 1996, nº 68].

${ }^{20}$ Artículo 15 de la Ley 1/1988, de 7 de enero, del Presidente, del Consejo de Gobierno y de la Administración de la Comunidad Autónoma de la Región de Murcia. Estas atribuciones aparecen ya en la norma que la antecedió, concretamente la Ley 1/1982, de 18 de octubre, de Gobierno y Administración Pública de la Comunidad Autónoma de la Región de Murcia (artículos 8 y 16).
} 
gresos, elaborará el anteproyecto de Ley de Presupuestos Generales de la Comunidad Autónoma de la Región de Murcia y lo someterá a la aprobación del Consejo de Gobierno».

En otras palabras, los anteproyectos remitidos por las Consejerías no son de iure vinculantes para el Consejero de Hacienda: son exclusivamente el soporte material a partir del cual elaborar un documento jurídico que servirá para el posterior debate del Consejo de Gobierno. Sin embargo, los acuerdos de Consejo de Gobierno se toman por minoría simple, correspondiéndole a su Presidente el voto de calidad en caso de empate ${ }^{21}$. En tales condiciones, aun en el caso en que el Consejero de Hacienda presentase un documento discrepante, en todo o en parte, de los anteproyectos remitidos por los restantes Consejeros, carecería de facto de capacidad para ejercer veto alguno en la fase de elaboración presupuestaria. Incluso en el caso de que su Anteproyecto de Ley difiriese de la mera integración aritmética de los anteproyectos remitidos por cada uno de los restante Consejeros, ese «veto eventual» podría ser corregido en el seno del propio Consejo de Gobierno.

En consecuencia, afirmamos que la fase «ejecutiva» se caracteriza por una organización jerárquica en la que el Presidente de la Comunidad Autónoma ocupa un papel preeminente frente al resto de miembros del Consejo de Gobierno. Si a ello sumamos la sucesión de mayorías absolutas que ha caracterizado la historia legislativa regional ${ }^{22}$, podemos afirmar que el Anteproyecto de Ley de Presupuestos es una expresión de la voluntad política del Presidente de la Comunidad Autónoma, y que ello excluye la necesidad de recurrir a prácticas de logrolling con el fin de conformar mayorías en el seno del Consejo de Gobierno para la aprobación de Proyectos de Ley de Presupuestos.

En cuanto a la fase «legislativa» de la elaboración del presupuesto, diremos que se inicia con la remisión del Proyecto de Ley por el Consejo de Gobierno a la Asamblea Regional de Murcia. Esta es, sin lugar a dudas, la fase a la que más atención han prestado los especialistas en las instituciones presupuestarias. El ámbito legislativo es, en una democracia parlamentaria, el ámbito en el que se concreta el proceso de elección colectiva: los miembros del órgano legislativo pasan a erigirse en titulares de las preferencias sociales conforme a las cuales han de asignarse los recursos presupuestarios. Por ello, los sistemas de debate y votación del presupuesto, su duración, su secuencia, etc. centran la atención en esta fase.

El debate de presupuestos se organiza en dos partes.

\footnotetext{
${ }^{21}$ Artículo 24.2 de la Ley 1/1988, de 7 de enero, del Presidente...

${ }^{22}$ Lo cual, en la fase ejecutiva se concreta en la formación de Gobiernos «monocolor». Entre 1983 y 1995 el PSOE obtuvo mayoría absoluta en las elecciones autonómicas. Desde 1995 hasta la actualidad otro tanto ha sucedido con el PP.
} 
Inicialmente se somete a debate, enmienda y votación la totalidad del Proyecto de Ley. Si alguna enmienda a la totalidad es aprobada (cosa que no ha sucedido en 21 años de experiencia autonómica en la Región de Murcia), el texto es devuelto al Gobierno regional, para su reelaboración conforme a los criterios que han fundamentado la enmienda; de lo contrario sigue su tramitación parlamentaria.

En una segunda parte, con el proyecto de totalidad aprobado, se somete a debate, enmienda y votación cada una de las secciones presupuestarias que lo integran.

La organización del debate parlamentario del Proyecto de Ley de Presupuestos, a efectos de la determinación del déficit público, es una norma de procedimiento «cerrada ${ }^{23}$. Decimos que es una norma «cerrada» porque en el debate de totalidad (primera fase del procedimiento legislativo) queda fijado el importe total del estado de gastos y de la previsión de ingresos de los Presupuestos Generales de la Comunidad Autónoma, así como de cada una de las secciones presupuestarias que lo integran ${ }^{24}$. A tal efecto el artículo 116 del Reglamento de la Asamblea Regional de Murcia (1988) establece: «4. Las enmiendas al proyecto de ley de presupuestos, que supongan aumentos de créditos en algún artículo o concepto, únicamente podrán ser admitidas a trámite si, además de cumplir los requisitos generales, proponen una baja de igual cuantía en la misma sección, salvo que se trate de enmiendas referidas a un programa financiado con créditos de diferentes secciones».

Ello es muy relevante porque, desestimadas las enmiendas a la totalidad, no cabe posibilidad alguna de modificar el importe global de los presupues-

\footnotetext{
${ }^{23}$ Véase nota 19. El debate del proyecto de Ley de presupuestos se rige por el procedimiento legislativo ordinario (Título V del Reglamento de la Asamblea Regional de Murcia), salvo lo dispuesto en el Capítulo IV, del Título VI de dicha norma. Hasta mediados de 1983 la Asamblea Regional de Murcia no dispuso de Reglamento propio, de modo que el debate sobre los primeros presupuestos autonómicos - los del ejercicio 1983- se ordenó mediante la aplicación del procedimiento legislativo establecido en el Reglamento del Congreso de los Diputados. Aun así este primer Reglamento no contenía ninguna regulación específica del debate presupuestario, de modo que se aplicaba el procedimiento establecido con carácter general para los debates legislativos. La aprobación del nuevo Reglamento de la Asamblea Regional de Murcia en 1988 subsanó esta deficiencia incluyendo una regulación específica para atender las peculiaridades del debate presupuestario (véase Acuerdo de la Asamblea Regional de Murcia 22 de abril de 1983 por el que se aprueba el Reglamento de la Asamblea Regional de Murcia). Posteriormente se aprobaría el Reglamento de la Asamblea Regional de Murcia de 14 de abril de 1988, reformado sucesivamente el 15 de julio de 1994, el 27 de junio de 1996 y el 15 de abril de 1999. En ningún caso tales modificaciones afectaron al Capítulo IV del Título VI del Reglamento, referente al proyecto de Ley de Presupuestos Generales de la Comunidad Autónoma de Murcia. Sobre la capacidad autonormativa de la Asamblea Regional de Murcia en materia de su propia organización el artículo 27.1 del Estatuto de Autonomía indica que «La Asamblea Regional, en el ejercicio de su autonomía, establece su propio Reglamento, aprueba su presupuesto y regula el Estatuto de sus miembros y el régimen de su personal. La aprobación del reglamento y su reforma precisan el voto final favorable de la mayoría de los miembros de la Asamblea». El Reglamento actualmente vigente trata de 13 de junio de 2002, fecha en la que se produjo la aprobación de una reforma global del mismo.
}

${ }^{24}$ Las Secciones presupuestarias son cada una de las unidades de elaboración presupuestaria diferenciada: cada Consejería constituye una sección presupuestaria y también cada Organismo Autónomo. 
tos en la fase siguiente, esto es, mediante las enmiendas parciales. Además, la iniciativa legislativa en materia presupuestaria es competencia exclusiva del Consejo de Gobierno ${ }^{25}$, es decir, nadie, salvo el Consejo de Gobierno puede proponer un proyecto de Ley de Presupuestos. En consecuencia, en el debate de totalidad los grupos parlamentarios sólo tienen la posibilidad de sumarse a la propuesta gubernamental o rechazarla (solicitando su reformulación), pero en ningún caso presentar un presupuesto alternativo ${ }^{26}$.

Pero no sólo el importe global de ingresos y gastos queda aprobado con el debate de totalidad. Implícitamente se aprueba el déficit público: en la fase de enmiendas parciales sólo se admiten aquellas que incrementando un crédito presupuestario proponen, al mismo tiempo, la reducción de otro crédito, dentro de la misma sección presupuestaria ${ }^{27}$. De esa manera los grupos políticos sólo pueden tratar de recomponer el gasto público pero en modo alguno alterar el objetivo de déficit público fijado por el Gobierno en el Proyecto de Ley.

En consecuencia, si el sistema de norma «cerrada» facilita las pretensiones del Gobierno en materia presupuestaria, la historia de mayorías absolutas, que ya hemos mencionado, refuerza el papel del poder ejecutivo. Según consta en la documentación parlamentaria, ninguna de las enmiendas a la totalidad presentadas por los distintos grupos parlamentarios logró nunca prosperar, y dado que las escasas enmiendas parciales aprobadas no podían legalmente afectar, ni a la totalidad del presupuesto, ni al importe del déficit público, puede afirmarse que el objetivo de déficit público ha sido, año tras año, el objetivo fijado por el Gobierno Regional.

Además, no existe diferencia alguna entre la organización de la fase de elaboración presupuestaria en función del color ideológico del partido en el poder: la organización jerárquica del poder ejecutivo, la correspondencia de liderazgo «Partido-Gobierno-Parlamento» y el sistema «cerrado» de enmienda presupuestaria son idénticos a lo largo de la historia autonómica de la Región de Murcia: tanto las etapas de mayoría absoluta del PSOE (1983-1995) como las del PP (1995-2003), comparten el mismo esquema de jerarquía y «unicidad» de liderazgo en el proceso presupuestario.

\footnotetext{
${ }^{25}$ Artículo 46 del Estatuto de Autonomía.

${ }^{26}$ Aunque ni el Estatuto de Autonomía ni la LHRM se refieren expresamente a la imposibilidad de presentar un texto alternativo al Proyecto de Ley de Presupuestos del Consejo de Gobierno, la Resolución de la Presidencia de la Asamblea Regional de Murcia, de 13 de diciembre de 1985, interpretativa del artículo 115 del Reglamento de 22 de abril de 1983, así lo establece taxativamente: «No ha lugar a la formulación, por los grupos parlamentarios, de enmiendas a la totalidad, con propuesta de texto alternativo, al proyecto de Ley de Presupuestos Generales de la Comunidad Autónoma».

${ }^{27}$ Salvo que se enmiende un programa presupuestario financiado con créditos de diferentes secciones presupuestarias (artículo 116.4 del Reglamento de la Asamblea Regional de Murcia).
} 


\section{DEBATE Y APROBACIÓN DEL PRESUPUESTO}

En virtud del principio de competencia, existe un reparto de papeles entre los poderes ejecutivo y legislativo en el proceso presupuestario, lo cual, en palabras de Domínguez Alonso (1983, p. 17), constituye «la médula de todo el derecho presupuestario» ${ }^{28}$. Este principio, que como el resto de los que rigen la hacienda regional está plasmado en el artículo 46 del Estatuto de Autonomía, confiere al poder ejecutivo la exclusiva de la iniciativa legislativa, de modo que sólo el Consejo de Gobierno puede presentar un proyecto de ley de presupuestos. Por su parte, al poder legislativo, encarnado en la Asamblea Regional, le confiere la competencia de examinar, enmendar y en su caso aprobar el proyecto de ley.

El proceso presupuestario nace en el ámbito del poder ejecutivo: en virtud de lo establecido en el artículo 31 de la Ley de Hacienda de la Región de Murcia $\left(\mathrm{LHRM}^{29}\right)$, la Consejería de Hacienda recabará de las restantes Consejerías los anteproyectos de estados de gastos de cada departamento y, tras examinar los referidos anteproyectos de gastos y la estimación de ingresos (por ella misma confeccionada), elaborará el anteproyecto de ley de Presupuestos Generales de la Comunidad Autónoma y lo someterá a la aprobación del Consejo de Gobierno.

El principio de temporalidad se refiere a la duración del presupuesto, que en nuestro caso coincide con el año natural. Como indica Palao Taboada (1987, p. 86), «la temporalidad del Presupuesto es consustancial a esta institución: el control político del gasto público exige que la autorización para llevarlo a cabo sea periódicamente renovada...Pero existen también en su favor razones de carácter financiero: la determinación periódica del estado de las cuentas públicas es un principio esencial al buen orden de éstas» ${ }^{30}$.

La eficacia de cada uno de los poderes en el cumplimiento de estos principios condiciona al otro. Los retrasos del Consejo de Gobierno en la aprobación del proyecto de ley de presupuestos provocan, a su vez, retrasos en el debate legislativo, llegando incluso a aprobarse el presupuesto con posterioridad al inicio del año natural, lo cual perjudica la fase de ejecución presupuestaria, fase que se inicia una vez que el ejecutivo recibe del legislativo el texto aprobado.

En el Cuadro 2 hemos consignado las fechas más relevantes en la tramitación presupuestaria, lo cual nos permite poner de manifiesto el grado de

\footnotetext{
${ }^{28}$ Véase M. Domínguez Alonso (1983), Presupuestos, Contabilización y Fiscalización en las Corporaciones Locales, Instituto de Estudios de la Administración Local, Madrid.

${ }^{29}$ Ley 3/1990, de 5 de abril, de Hacienda de la Región de Murcia. Sustituida por el Decreto Legislativo $1 / 1999$, de 2 de diciembre, por el que se aprueba el texto Refundido de la Ley de Hacienda de la Región de Murcia.

${ }^{30}$ Véase C. Palao Taboada (1987), Derecho Financiero y Tributario, Editorial Colex, Madrid.
} 
cumplimiento de los principios que estamos analizando. En él se contienen las fechas de aprobación del proyecto de ley por el ejecutivo (Acuerdo del Consejo de Gobierno), la fecha de entrada del proyecto en la Asamblea Regional (Registro en la Cámara) y la de publicación de la ley aprobada en el Boletín Oficial de la Región de Murcia (BORM).

Según lo establecido en el artículo 46.2 del Estatuto de Autonomía, el Consejo de Gobierno debe presentar el proyecto de ley de presupuestos al órgano legislativo antes de iniciarse el último trimestre del año previo al de su entrada en vigor ${ }^{31}$. En 1998, dicho artículo fue modificado ${ }^{32}$, fijando la fecha límite para la remisión del proyecto de ley a la Asamblea Regional de Murcia en dos meses antes de la entrada en vigor del presupuesto ${ }^{33}$.

En el Cuadro 3 hemos registrado los datos que resumen los incumplimientos del principio de temporalidad en el proceso de elaboración del presupuesto. Para cada presupuesto hemos computado la duración (en días) del proceso ${ }^{34}$, el retraso en la entrada en la Cámara del proyecto de Ley $^{35}$ y el retraso en la aprobación de la ley de presupuestos ${ }^{36}$ (valores negativos implican retrasos y viceversa).

Como se aprecia en el Cuadro 3, hasta 1995 inclusive el proyecto de Ley de presupuestos tuvo su entrada en la Asamblea Regional de Murcia con notable retraso sobre la fecha oficial. Con tales retrasos, causados por el Consejo de Gobierno, no es de extrañar que las leyes de presupuestos entrasen en vigor una vez iniciado el ejercicio presupuestario contraviniendo lo dispuesto en el artículo 46.5 del Estatuto de Autonomía: así sucedió con todos los presupuestos comprendidos entre 1983 y 1990. En los ejercicios 1983, 1984 y 1990 el retraso en la entrada en vigor superó incluso los dos meses. Tales retrasos obligaron a prorrogar los presupuestos en vigor, operación que se produce de forma automática ${ }^{37}$ una vez superado el plazo legal de aprobación de la ley de presupuestos, según lo establecido en el artículo mencio-

\footnotetext{
${ }^{31}$ Es decir, el 30 de septiembre.

32 Mediante Ley Orgánica 1/1998, de 15 de junio, de Reforma del Estatuto de Autonomía para la Región de Murcia.

${ }^{33}$ Es decir, el 31 de octubre.

${ }^{34}$ Calculado como la diferencia entre la fecha de publicación de la Ley de Presupuestos y la fecha de entrada del proyecto de Ley en el registro de la Asamblea Regional de Murcia.

${ }^{35}$ Calculado como la diferencia entre la fecha de entrada del proyecto de ley en el registro de la Asamblea Regional de Murcia y la fecha establecida en el artículo 46.2 del Estatuto de Autonomía (según redacción vigente en cada momento).

${ }^{36}$ Calculado como la diferencia entre la fecha de publicación oficial de la ley de presupuestos y el 31 de diciembre del año precedente a su entrada en vigor.

${ }^{37}$ A pesar de esa automaticidad, prevista en el artículo 46.5 del Estatuto de Autonomía, en 1983 se aprobó una Ley autorizando la prórroga de los Presupuestos de 1982, en previsión de la tardanza con la que se habrían de aprobar los del ejercicio en curso. Dicha Ley es la 2/1983 de 4 de febrero, de Prórroga del Presupuesto de 1982 y Otras Medidas Presupuestarias de Urgencia para el Ejercicio 1983.
} 
nado. La entrada en vigor de la LHRM supuso un giro radical en este aspecto, publicándose dentro del plazo legalmente previsto todos los presupuestos de los ejercicios comprendidos entre 1991 y 2003.

A pesar del retraso con que llegaba a sus manos, el legislativo no se privó de cumplir a fondo con su deber de examinar y enmendar los proyectos de ley de presupuestos. Buena cuenta de ello dan los datos que se consignan en el Cuadro 4, relativos a las enmiendas a la totalidad y enmiendas parciales presentadas por los distintos Grupos Parlamentarios de la Asamblea Regional.

CuAdro 2

Trámite de los proyectos de Ley de Presupuestos

\begin{tabular}{|c|c|c|c|}
\hline Proyecto & $\begin{array}{c}\text { Acuerdo de Consejo } \\
\text { de Gobierno }\end{array}$ & $\begin{array}{c}\text { Registro } \\
\text { en la Cámara }\end{array}$ & $\begin{array}{c}\text { Publicación } \\
\text { BORM }\end{array}$ \\
\hline 1983 & $10 / 02 / 83$ & $04 / 03 / 83$ & $08 / 04 / 83$ \\
1984 & $24 / 01 / 84$ & $30 / 01 / 84$ & $31 / 05 / 84$ \\
1985 & $29 / 11 / 84$ & $07 / 12 / 84$ & $30 / 01 / 85$ \\
1986 & $13 / 11 / 85$ & $20 / 11 / 85$ & $28 / 01 / 86$ \\
1987 & $12 / 12 / 86$ & $15 / 12 / 86$ & $02 / 02 / 87$ \\
1988 & $26 / 11 / 87$ & $30 / 11 / 87$ & $01 / 02 / 88$ \\
1989 & $07 / 11 / 88$ & $08 / 11 / 88$ & $28 / 01 / 89$ \\
1990 & $22 / 12 / 89$ & $29 / 12 / 89$ & $28 / 02 / 90$ \\
1991 & $05 / 10 / 90$ & $29 / 10 / 90$ & $28 / 12 / 90$ \\
1992 & $18 / 10 / 91$ & $28 / 10 / 91$ & $30 / 12 / 91$ \\
1993 & $30 / 10 / 92$ & $30 / 10 / 92$ & $30 / 12 / 92$ \\
1994 & $05 / 11 / 93$ & $09 / 11 / 93$ & $29 / 12 / 93$ \\
1995 & $28 / 10 / 94$ & $10 / 11 / 94$ & $30 / 12 / 94$ \\
1996 & $27 / 09 / 95$ & $30 / 09 / 95$ & $27 / 12 / 95$ \\
1997 & $25 / 09 / 96$ & $30 / 09 / 96$ & $30 / 12 / 96$ \\
1998 & $26 / 09 / 97$ & $30 / 09 / 97$ & $30 / 12 / 97$ \\
1999 & $29 / 10 / 98$ & $29 / 10 / 98$ & $28 / 12 / 98$ \\
2000 & $28 / 10 / 99$ & $29 / 10 / 99$ & $31 / 12 / 99$ \\
2001 & $27 / 10 / 00$ & $30 / 10 / 00$ & $30 / 12 / 00$ \\
2002 & $27 / 10 / 01$ & $31 / 10 / 01$ & $31 / 12 / 01$ \\
2003 & $31 / 10 / 02$ & $31 / 10 / 02$ & $31 / 12 / 02$ \\
\hline
\end{tabular}

Fuente: Archivo de la Asamblea Regional de Murcia. 


\section{Cuadro 3}

Duración de la tramitación presupuestaria (Días)

\begin{tabular}{|c|r|c|c|}
\hline Presupuesto & Duración & Retraso entrada & Retraso aprobación \\
\hline 1983 & 35 & -155 & -98 \\
1984 & 122 & -122 & -152 \\
1985 & 54 & -68 & -30 \\
1986 & 69 & -51 & -28 \\
1987 & 49 & -76 & -33 \\
1988 & 63 & -61 & -32 \\
1989 & 81 & -39 & -28 \\
1990 & 61 & -90 & -59 \\
1991 & 60 & -29 & 3 \\
1992 & 63 & -28 & 1 \\
1993 & 61 & -30 & 1 \\
1994 & 50 & -40 & 2 \\
1995 & 50 & -41 & 1 \\
1996 & 88 & 0 & 4 \\
1997 & 91 & 0 & 1 \\
1998 & 91 & 0 & 1 \\
1999 & 60 & 2 & 0 \\
2000 & 63 & 2 & 0 \\
2001 & 61 & 1 & 1 \\
2002 & 62 & 0 & 0 \\
2003 & 62 & 0 & 1 \\
\hline
\end{tabular}

Fuente: Elaboración propia a partir de Cuadro 2. 


\section{Cuadro 4}

Enmiendas a los Proyectos de Presupuesto

\begin{tabular}{|c|c|c|}
\hline Proyecto de Ley & A la Totalidad & Parciales \\
\hline 1983 & 1 & 65 \\
\hline 1984 & 2 & 455 \\
\hline 1985 & 3 & 449 \\
\hline 1986 & 3 & 870 \\
\hline 1987 & 1 & 1.175 \\
\hline 1988 & 3 & 565 \\
\hline 1989 & 3 & 337 \\
\hline 1990 & 3 & 341 \\
\hline 1991 & 3 & 394 \\
\hline 1992 & 2 & 586 \\
\hline 1993 & 2 & 1.093 \\
\hline 1994 & 2 & 384 \\
\hline 1995 & 2 & 490 \\
\hline 1996 & 2 & 437 \\
\hline 1997 & 2 & 663 \\
\hline 1998 & 2 & 681 \\
\hline 1999 & 2 & 829 \\
\hline 2000 & 2 & 1.071 \\
\hline 2001 & 2 & 983 \\
\hline 2002 & 2 & 1.139 \\
\hline 2003 & 2 & 1.033 \\
\hline
\end{tabular}

Fuente: Archivo de la Asamblea Regional. 


\section{LIQUIDACIÓN DEL PRESUPUESTO. DISCRECIONALIDAD}

La liquidación del presupuesto es el conjunto de actos que tienen por finalidad conocer el grado de ejecución del presupuesto, así como las condiciones jurídicas y económicas en las que ha tenido lugar esa ejecución. Desde una perspectiva material, la liquidación se concreta en la elaboración de la Cuenta General, un complejo conjunto de documentos contables mediante el cual es posible conocer la actividad financiera desarrollada por una Administración.

Sin embargo, a pesar de la dimensión contable que reviste la Cuenta General, la liquidación del presupuesto es mucho más que un mero «episodio contable» en el curso del proceso presupuestario. La liquidación del presupuesto implica también una dimensión jurídica y una dimensión política. Dimensión jurídica en la medida en que con la liquidación se abre un proceso de escrutinio cuya competencia recae sobre el Tribunal de Cuentas como supremo órgano fiscalizador de las cuentas y de la gestión económica del $E \operatorname{stado}^{38}$. Dimensión política porque con la liquidación se hace posible el control parlamentario que el artículo 46.1 del Estatuto de Autonomía otorga a la Asamblea Regional de Murcia ${ }^{39}$. También aquí podemos encontrar la huella del sistema presupuestario.

De los Informes que periódicamente elabora el Tribunal de Cuentas sobre la Cuenta General de la Comunidad Autónoma de la Región de Murcia, podemos extraer información muy valiosa acerca de las principales características del proceso presupuestario.

Del contenido de los citados Informes se desprende, año tras año, una retahíla de conclusiones negativas; conclusiones que se extienden, incluso, a ejercicios presupuestarios posteriores a la entrada en vigor de la LHRM (1990). En particular cabe resaltar que en todo el periodo fiscalizado, al Tribunal de Cuentas le ha sido imposible realizar un control de eficiencia dado que en la Cuenta General nunca se incluye una Memoria justificativa del coste y rendimiento de los servicios públicos, ni se ha desarrollado un sistema de contabilidad analítica que permita la formación de dicha Memoria. Igualmente se echa en falta de forma concreta y precisa la determinación de los objetivos o fines a cumplir en los respectivos programas presupuestarios, así como los indicadores que permitan medir el grado de cumplimiento de los objetivos, ni de los grados de eficiencia y economía. Por ejemplo, el Informe correspondiente a 2000 afirma en su apartado 1.4: «Los programas del presu-

\footnotetext{
${ }^{38}$ Artículo 136.1 de la Constitución Española.

${ }^{39} \mathrm{Y}$ aún podríamos referirnos a una dimensión económica, en la medida en que la información contenida en la Cuenta General, y en su posterior fiscalización, debiera servir para retroalimentar y perfeccionar el sistema presupuestario regional.
} 
puesto de gastos de la Comunidad Autónoma para el ejercicio 2000 no contienen, de una forma concreta y precisa, la determinación de los objetivos o fines a cumplir, ni los indicadores que permitan medir su grado de cumplimiento. Asimismo, la no implantación de contabilidad analítica, motiva que no sea posible conocer y analizar objetivamente el coste y rendimiento de los servicios públicos». Esta observación se reitera en todos los Informes. Esta es otra constatación adicional de que tras el pretendido sistema de «Presupuestación por Programas» sigue existiendo un sistema de Presupuesto Administrativo, carente de la metodología de aquél.

Un aspecto fundamental de la ejecución presupuestaria es el papel desempeñado por las modificaciones presupuestarias. Su régimen es una pieza imprescindible para configurar el mapa de normas de procedimiento que integran el proceso presupuestario autonómico.

Para una valoración global de la importancia de las modificaciones presupuestarias comenzaremos por examinar su evolución en términos cuantitativos en los sucesivos presupuestos de la Comunidad Autónoma de la Región de Murcia. Para ello hemos comparado, para cada año, el importe total de las modificaciones con el presupuesto inicial de gastos respectivo ${ }^{40}$.

En cuanto al volumen de las modificaciones debe advertirse que, para aquellas que tienen un importe negativo (bajas por anulación de créditos), se ha tomado el valor absoluto, mientras que para aquellas que no alteran el volumen total del presupuesto (transferencias de crédito, redistribuciones y habilitaciones) hemos computado tan solo el «lado» positivo de las modificaciones, para evitar duplicar su importe y con ello, sesgar al alza su impacto presupuestario.

Estos resultados se exponen en el Cuadro 5. En la segunda columna de dicho Cuadro hemos consignado el importe total de las modificaciones presupuestarias en valores absolutos de cada año, en la tercera columna hemos registrado el importe del presupuesto inicial de gastos y en la cuarta el importe relativo de las modificaciones presupuestarias como porcentaje del presupuesto inicial de gastos.

La primera característica a destacar es el elevado impacto que han tenido las modificaciones en los sucesivos ejercicios presupuestarios: tal y como puede verse en el Cuadro 5, por término medio las modificaciones de crédito han representado el $35,0 \%$ del presupuesto de gastos inicialmente aprobado, llegando en numerosas ocasiones a superar el 50\% (años 1983, 1985, 1986, $1988,1989,1993$ y 2002). Es decir, el presupuesto que maneja el poder eje-

\footnotetext{
${ }^{40}$ La razón por la que establecemos la comparación con el presupuesto inicial, y no con el presupuesto definitivo o el presupuesto ejecutado, es sencilla: en el presupuesto inicial se plasma la voluntad del legislador y en ese sentido es una magnitud más «homogénea» que el presupuesto definitivo (afectado por las propias modificaciones presupuestarias) o el presupuesto ejecutado.
} 
CuAdro 5

Modificaciones presupuestarias.

Impacto en el presupuesto

(Millones de pesetas)

\begin{tabular}{|c|c|c|c|}
\hline AÑO & $\begin{array}{c}\text { Total } \\
\text { modificaciones }\end{array}$ & $\begin{array}{c}\text { Presupuesto inicial } \\
\text { Gastos }\end{array}$ & $\%$ \\
\hline 1983 & 5.640 & 10.160 & $55,5 \%$ \\
1984 & 7.135 & 17.101 & $41,7 \%$ \\
1985 & 12.917 & 23.774 & $54,3 \%$ \\
1986 & 21.394 & 30.921 & $69,2 \%$ \\
1987 & 10.565 & 33.253 & $31,8 \%$ \\
1988 & 21.816 & 38.906 & $55,6 \%$ \\
1989 & 39.371 & 50.958 & $76,7 \%$ \\
1990 & 16.929 & 61.927 & $27,1 \%$ \\
1991 & 16.687 & 66.783 & $24,8 \%$ \\
1992 & 13.200 & 70.854 & $18,5 \%$ \\
1993 & 45.377 & 77.932 & $57,8 \%$ \\
1994 & 8.468 & 74.639 & $10,6 \%$ \\
1995 & 13.268 & 82.799 & $15,9 \%$ \\
1996 & 22.339 & 97.369 & $22,8 \%$ \\
1997 & 26.936 & 127.550 & $20,7 \%$ \\
1998 & 27.806 & 141.190 & $19,3 \%$ \\
1999 & 63.144 & 149.661 & $41,3 \%$ \\
2000 & 37.214 & 258.514 & $14,3 \%$ \\
2001 & 35.168 & 270.103 & $12,9 \%$ \\
2002 & 166.394 & 282.180 & $58,5 \%$ \\
2003 & 25.805 & 447.846 & $5,8 \%$ \\
\hline & & Media & $35,0 \%$ \\
\hline
\end{tabular}

Fuente: Elaboración propia a partir de la Cuenta General e Informes de Fiscalización del Tribunal de Cuentas.

cutivo es significativamente distinto (en lo cualitativo y en lo cuantitativo) del aprobado por el legislador. Grosso modo, ello implica que más de la tercera parte del presupuesto ejecutado no se corresponde, ni cuantitativa, ni cualitativamente, con lo inicialmente aprobado por la Asamblea Regional de Murcia. De este modo, se relativiza la importancia de la fase de elaboración presupuestaria que analizamos en el epígrafe anterior. En otras palabras, el presupuesto sigue inmerso en un proceso de elaboración más allá de los límites legalmente establecidos para su elaboración debate y aprobación. El debate legislativo que tiene lugar en el último trimestre del año es tan sólo 
un momento (importante sin duda) en la secuencia que nos conduce hacia el «verdadero» presupuesto.

La segunda característica es la tendencia creciente en el importe nominal de las modificaciones, tendencia que en términos relativos se ve enmascarada por el mayor ritmo de crecimiento que registra el volumen total del presupuesto de gastos.

Ambas características indican que en la historia presupuestaria de la Comunidad Autónoma de la Región de Murcia ha sido (y es aún hoy día) práctica común recurrir a las modificaciones presupuestarias, de modo que el presupuesto del que finalmente dispone el poder ejecutivo difiere sustancialmente del aprobado por el legislador, tanto en su importe como en su distribución.

Además, buena parte de las modificaciones presupuestarias refleja exclusivamente la voluntad del poder ejecutivo, de modo que actúa como mecanismo para alterar el equilibrio de poderes en el proceso presupuestario a favor de este. En otras palabras, las modificaciones presupuestarias aportan una creciente discrecionalidad al sistema presupuestario.

Para ponderar esta afirmación hemos tratado de establecer dos categorías de modificaciones presupuestarias, clasificándolas en función del papel que el poder legislativo y el poder ejecutivo juegan en las mismas. Por un lado tendríamos aquellas modificaciones presupuestarias que inequívocamente se aprueban en el ámbito legislativo al ser la Asamblea Regional de Murcia el órgano que las aprueba (créditos extraordinarios y suplementos de crédito), o bien no deja al ejecutivo más margen que el de ampliar el alcance cuantitativo de una política preestablecida por el legislativo (ampliaciones de crédito). A esta categoría la hemos denominado modificaciones presupuestarias no discrecionales. En el extremo opuesto tenemos lo que hemos denominado modificaciones presupuestarias discrecionales: son aquellas cuya aprobación depende exclusivamente de la voluntad del poder ejecutivo, de modo que pueden dar lugar a una transformación sustancial (tanto cuantitativa como cualitativa) de las preferencias políticas expresadas por el órgano legislativo al aprobar el presupuesto. Aquí hemos incluido las generaciones de crédito, las transferencias de crédito y las bajas por anulaciones de crédito ${ }^{41}$.

En realidad, hay dos tipos de modificaciones (las incorporaciones de remanente de crédito y las bajas por anulación de créditos) en los que la calificación de la discrecionalidad plantea serios problemas tanto de naturaleza metodológica como conceptual.

En las incorporaciones de remanente de crédito hallamos, en apariencia, una fuerte discrecionalidad: el legislador establece como principio general la

\footnotetext{
${ }^{41}$ No aprobadas mediante Ley.
} 
anulación de aquellos créditos que al finalizar el ejercicio presupuestario no hayan quedado afectados al cumplimiento de obligaciones reconocidas, estableciendo a continuación un catálogo de créditos potencialmente incorporables $^{42}$ y otros de obligada incorporación. A partir de ahí las incorporaciones se podrían considerar como una acción discrecional del poder ejecutivo. Sin embargo, un planteamiento tan inmediato como este es engañoso: la posibilidad de efectuar incorporaciones requiere la existencia de remanente de crédito, remanente que podría obedecer, entre otras razones, a una acción deliberada de no-ejecución del presupuesto por parte del Gobierno. Esa noejecución se convalida en el momento en que pudiendo incorporar el remanente al año siguiente, el ejecutivo decide no hacerlo, de modo que la discrecionalidad consistiría en la omisión de la incorporación. Nótese, por ejemplo, el tratamiento dado por la LHRM a la incorporación de los créditos extraordinarios aprobados en los dos últimos meses del ejercicio presupuestario y no ejecutados: el Consejero de Hacienda dispone de potestad discrecional para proceder o no a dicha incorporación, esto es, puede, mediante la omisión de la incorporación, dejar sin eficacia una norma jurídica con rango de Ley. ¿No es eso discrecionalidad? Este carácter dicótomo de las incorporaciones de remanentes de crédito nos ha llevado a excluir las incorporaciones del montante de las modificaciones discrecionales.

En cuanto a las bajas por anulación, su particularidad reside en que han sido utilizadas indistintamente por el poder legislativo y el ejecutivo, de modo que sólo podemos considerar discrecionales las bajas efectuadas por este último sin que medie mandato legislativo. Por ello hemos excluido del cómputo total de modificaciones presupuestarias discrecionales aquellas bajas efectuadas directamente por Ley ${ }^{43}$.

Hechas estas aclaraciones, en el Cuadro 6 hemos registrado los datos correspondientes a las modificaciones discrecionales en comparación con el presupuesto inicial de gastos y el total de modificaciones potenciales. Como puede comprobarse en dicho cuadro, la discrecionalidad es una característica cada vez más relevante en el sistema de modificaciones presupuestarias: en el conjunto del periodo 1983-2003, el 62,5\% de las modificaciones efectuadas tuvieron carácter discrecional. Además, se aprecia la importancia creciente de las mismas. Ello implica una sustitución del papel del legislador en el proceso de reelaboración del presupuesto que tiene lugar una vez aprobado este en la fase legislativa.

En el Cuadro 6 podemos identificar ejercicios presupuestarios en los que la actividad discrecional del Gobierno regional ha sido especialmente activa: se trata de los ejercicios 1986, 1993, 1994, 1995, 1996, 1999, 2000, 2001, 2002 y 2003, en todos los cuales se han superado el 50\% sobre el total de

\footnotetext{
${ }^{42}$ Artículo 36 de la LHRM.

${ }^{43}$ A saber: 380`3 millones de pesetas en 1993, 1.791 millones de pesetas en 1996, 14.820 millones de pesetas en 1997 y 14.618 millones de pesetas en 1998.
} 
modificaciones. El elevado importe de las modificaciones del año 1986 se explica por el proceso de reorganización administrativa llevado a cabo en ese ejercicio $^{44}$ y que en el ámbito presupuestario se tradujo en un cuantioso importe de transferencias de crédito. En el año 1989 el elevado grado de discrecionalidad obedece, nuevamente, a las elevadas transferencias de crédito, originadas por la reorganización administrativa llevada a $\mathrm{cabo}^{45}$, así como al

\section{CuAdro 6}

Modificaciones presupuestarias discrecionales

(Generaciones, Transferencias y Bajas)

\begin{tabular}{|c|c|c|}
\hline AÑO & $\begin{array}{c}\text { Importe } \\
\text { (Millones de ptas.) }\end{array}$ & $\begin{array}{c}\text { \% sobre total } \\
\text { modificaciones }\end{array}$ \\
\hline 1983 & 534 & $9,5 \%$ \\
1984 & 1.143 & $16,0 \%$ \\
1985 & 3.277 & $25,4 \%$ \\
1986 & 11.242 & $52,5 \%$ \\
1987 & 2.026 & $19,2 \%$ \\
1988 & 4.689 & $21,5 \%$ \\
1989 & 15.306 & $38,9 \%$ \\
1990 & 8.176 & $48,3 \%$ \\
1991 & 8.019 & $48,1 \%$ \\
1992 & 5.039 & $38,2 \%$ \\
1993 & 42.034 & $92,6 \%$ \\
1994 & 8.454 & $99,8 \%$ \\
1995 & 12.432 & $93,7 \%$ \\
1996 & 17.579 & $78,7 \%$ \\
1997 & 9.218 & $34,2 \%$ \\
1998 & 10.803 & $38,9 \%$ \\
1999 & 55.064 & $87,2 \%$ \\
2000 & 33.837 & $90,9 \%$ \\
2001 & 29.318 & $83,4 \%$ \\
2002 & 156.719 & $94,2 \%$ \\
2003 & 21.982 & $85,2 \%$ \\
\hline & Media & $62,5 \%$ \\
\hline
\end{tabular}

Fuente: Elaboración propia a partir de la Cuenta general de Informes de Fiscalización del Tribunal de Cuentas.

\footnotetext{
${ }^{44}$ Véase Decreto 7/1986 y Decreto 40/1986 de la Presidencia de la Comunidad Autónoma de la Región de Murcia.

${ }^{45}$ Véase Decreto 71/1989 de la Presidencia de la Comunidad Autónoma de la Región de Murcia.
} 
cambio de aplicación presupuestaria de los fondos destinados a financiar la instalación de General Electric Plastics España ${ }^{46}$. En el año 1993 se suprime la Agencia Regional de Medio Ambiente y, como resultado de la correspondiente reorganización administrativa, se produce un voluminoso caudal de transferencias de crédito. En cuanto al ejercicio 2002 y 2003, el elevado porcentaje de modificaciones discrecionales corresponde a la culminación del proceso negociador de transferencias sanitarias.

En definitiva podemos afirmar que, frente a las pretensiones de los sucesivos Gobiernos al abanderar unas u otras reformas presupuestarias, el estado actual del sistema presupuestario de la Comunidad de Murcia es el de un Presupuesto Administrativo cuya sofisticación ha ido creciendo por el efecto de tales reformas, dentro de las cuales cabe destacar:

a) La introducción del Presupuesto por Programas ${ }^{47}$ (1985).

b) La presupuestación de los Beneficios Fiscales (1996).

c) La presentación del presupuesto consolidado a nivel funcional (1997).

d) El cumplimiento de los plazos de elaboración y aprobación del presupuesto (1990).

e) Información del estado de compromisos con cargo a ejercicios futuros (1996).

f) Información territorializada sobre proyectos de inversión ${ }^{48}$ (2002).

g) Difusión de las Leyes de Presupuestos, la Cuenta General y los Informes de Fiscalización del Tribunal de Cuentas vía Internet (2002).

\section{CONCLUSIONES}

La lentitud y la provisionalidad han marcado el desarrollo del diseño del proceso presupuestario en la Comunidad Autónoma de la Región de Murcia, diseño que no alcanza su madurez hasta 1990, año en que se aprueba la Ley 3/1990, de 5 de abril, de Hacienda de la Región de Murcia, su Ley Presu-

\footnotetext{
${ }^{46}$ Esta última modificación, por importe de 3.100 millones de pesetas, fue manifiestamente ilegal, tal y como lo advirtió el Tribunal de Cuentas en el Informe de Fiscalización de 1993: mediante transferencia de crédito se disminuyó el importe de un crédito extraordinario aprobado por Ley 3/1993, pese a que la LHRM en su artículo 41 prohíbe taxativamente que las transferencias de crédito afecten a los créditos extraordinarios concedidos durante el ejercicio.

${ }^{47}$ Hemos pasado de 68 programas presupuestarios en 1985 a 134 en 2002.

${ }^{48}$ Desde 2002 el proyecto de ley de presupuestos contiene en el Tomo V un anexo con los proyectos de inversión por municipios. La Oficina Presupuestaria propuso que en las liquidaciones presupuestarias periódicamente remitidas por la Intervención General se aportase información relativa al estado de ejecución de tales proyectos. La propuesta fue rechazada por las razones expuestas (ver nota anterior).
} 
puestaria. Hasta esa fecha, es la ley de presupuestos de cada año la fuente fundamental de organización del proceso presupuestario. Y por ese mismo mecanismo se introducirán cada año modificaciones a la citada norma hasta la aprobación, en 1999, de su Texto Refundido.

Si consideramos globalmente el periodo 1983-2003, podemos afirmar que el sistema presupuestario autonómico se caracteriza por los elementos siguientes:

a) Preponderancia del poder ejecutivo sobre el poder legislativo en las distintas fases del presupuesto.

b) Evolución hacia un sistema presupuestario cada vez más sofisticado que, sin embargo, no supera el modelo de Presupuesto Administrativo.

La preponderancia del poder ejecutivo sobre el poder legislativo queda patente en la exclusividad de la iniciativa legislativa en materia presupuestaria, en el carácter cerrado del sistema de votación y enmienda del presupuesto, y en la unidad de liderazgo Gobierno-partido-grupo parlamentario. A lo anterior hay que unir un generoso sistema de modificaciones presupuestarias, crecientemente discrecional, que deja en manos del Gobierno Regional la fase de elaboración del presupuesto más allá del momento en que la Asamblea Regional de Murcia culmina su aprobación. Las modificaciones presupuestarias suponen cada año, por término medio, el 35,0\% del presupuesto inicial. De ellas, por término medio, el $62,5 \%$ son aprobadas con la intervención exclusiva del Gobierno Regional.

La creciente sofisticación del sistema presupuestario se manifiesta en la mayor diversidad de documentos que acompañan al proyecto de presupuesto y en el elevado número de programas presupuestarios que lo integran. Sin embargo, ninguna de las reformas anunciadas ha introducido elementos típicos del sistema PPBS, como el análisis coste beneficios para la selección de programas, por lo cual seguimos inmersos en un Presupuesto Administrativo, si bien cada vez más sofisticado. 